\title{
NÂNG CAO SỰ GẮN KẾT CỦA NHÂN VIÊN VỚI TỔ CHỨC: NGHIÊN CỨU THỰC NGHIẸM TẠI CÔNG TY TRÁCH NHIỆM HỮU HẠN HÙNG CÁ
}

\author{
Bùi Nhất Vương ${ }^{1}$, Nguyễn Thị Ngọc Châu²
}

\author{
${ }^{1}$ Trường Đại học Tôn Đức Thắng \\ ${ }^{2}$ Công ty TNHH Hùng Cá \\ nhatvuongal@gmail.com \\ Ngày nhận bài: 06/02/2020; Ngày duyệt đăng: 20/5/2020
}

\section{Tóm tắt}

Nguồn nhân lực được coi là một nguồn lực quan trọng vì nó thúc đẩy tất cả các yếu tố khác bao gồm vốn, thiết bị, thông tin và nguồn tài chính. Nguồn nhân lực bao gồm các tài sản vô hình nhu văn hóa, kỹ năng, năng lực và tuoong tác xã hội giữa moi người, và nhóm.... Nếu xư lý tốt nguồn nhân lực có thể cung cấp một lợi thế cạnh tranh, nhưng khi xủ lý sai, chúng sẽ dẫn đến áp lực cho công ty. Trong thế giới toàn cầu hóa hiện nay, các tổ chức nên chú tâm đến nguồn nhân lục để mà họ có thể tồn tại và duy trì hiệu quả. Tuy nhiên, hiệu quả sẽ không thể đạt được nếu không có sụ gắn kết của nhân viên. Do đó, muc tiêu của nghiên cứu hiện tại là để khám phá các nhân tố ảnh hưởng đến sự gắn kết của nhân viên tại công ty Hùng Cá. Dũ liệu khảo soát đã thu thập tù 67 nhân viên văn phòng và 260 công nhân (tổng $N=327$ ) tại công ty Hùng Cá đã được phân tích để cung cấp bằng chứng. Kết quả tù̀ phân tích hồi quy bội bởi sử dụng phần mềm SPSS đã xác định rằng Thu nhập, Khen thương và phúc lợi, Người quản lý trực tiếp, Môi truờng làm việc, Đồng nghiệp, Văn hóa tổ chức, và Co họi thăng tiến đã có khuynh huoóng liên kết tích cực với sụ gắn kết của nhân viên. Những phát hiện chính của nghiên cứu này cung cấp các hàm ý thưc tiễn cho công ty. Nó ngu ý rằng công ty nên cải thiện nhũng yếu tố này để duy trì và nâng cao sụ gắn kết của nhân viên.

Tù khóa: co hội nghề nghiệp, đồng nghiệp, khen thưởng và phúc lợi, môi trường làm việc, thu nhập, sự gắn kết của nhân viên.

\section{A model of factors enhancing organizational commitment: Evidence from Hung Ca limited company}

\begin{abstract}
Human resources are seen to be an important resource since it drives all the other factors which include capital, equipment, information, and financial resources. This encompasses intangible assets which include culture, skill, competence, and social interaction between people, and teams.... If handled well human resources can provide a competitive advantage, but when mishandled, they lead to corporate stress. In the current world of globalization, organizations should perform for them to survive and remain effective. Good performance and effectiveness are not achieved without employee
\end{abstract}


commitment. Therefore, the present study aims to explore factors affecting employee commitment at Hung Ca company. Survey data collected from 67 white-collar workers and 260 blue-collar workers (total $N=327$ ) at Hung Ca company was analyzed to provide evidence. Results from the multiple regression analysis by using SPSS software revealed that income, reward and well-being, supervisor support, working environment, co-worker support, organizational culture, and career opportunity tended to associate positively with employee commitment. The main findings of this article provide some empirical implications for the company. It implies that the company should improve these factors to retain and enhance employee commitment.

Keywords: career opportunity, co-worker support, reward and well-being, working environment, income, employee commitment.

\section{Giói thiệu}

Chúng ta biết rằng tổ chức là do con người quản lý và gây dựng lên. Do đó, không có con người, tổ chức không tồn tại. Vì vậy, bất kỳ loại hình tổ chức nào, muốn đạt được thành công trong hoạt động của mình đều phải chú trọng đến vai trò quan trọng của yếu tố con người. Thật vậy, chúng ta đều biết rằng muốn đi đường xa nên đi cùng bạn đồng hành; muốn phát triển bền vững nên có người cộng sự bên cạnh. Chúng ta không thể làm được gì nếu chỉ mình ta cô độc giữa cuộc đời này. Đối với một doanh nghiệp cũng vậy, dù người lãnh đạo có tài ba đến đâu nhưng nếu không có nhân viên giỏi, không có nhân viên trung thành cùng góp sức thì người lãnh đạo cũng sẽ kiệt sức và chí lớn của người lãnh đạo ấy cũng không thể thành công. Vì vậy, sự gắn kết của nhân viên với tổ chức được xem là chìa khóa để tổ chức phát triển bền vững. Bởi không có một công ty nào, dù quy mô lớn hay nhỏ, có thể giành thắng lợi trong dài hạn mà không có những nhân viên đầy nghị lực, luôn tin tưởng vào sứ mệnh của công ty và hiểu phải làm thế nào để thực hiện được sứ mệnh đó. Do đó, các nhà quản trị luôn phải có những người dám cùng mình vượt qua bão tố giữa đại dương. Chúng ta cứ thử tưởng tượng rằng một tổ chức cứ thay đổi nhân sự thường xuyên thì sẽ như thế nào. Ngoài việc các tổ chức phải chịu tổn thất từ việc tuyển người thay thế, bởi vì mỗi nhân viên khi chuyển đi mang theo các giá trị thuộc về nguồn vốn con người, các kiến thức, kỹ năng và cả các bí quyết của tổ chức thì sự thay đổi ấy còn ảnh hưởng đến tâm lý làm việc của những nhân viên ở lại của tổ chức. Vì tác giả cho rằng tâm của người nhân viên sẽ động. Họ sẽ cảm thấy bất an, cảm thấy chán nản khi đồng nghiệp của mình nghỉ việc nhiều và điều ấy sẽ ảnh hưởng đến hiệu quả công việc.

Công ty TNHH Hùng Cá là một công ty gia đình, hoạt động trong lĩnh vực nuôi trồng, chế biến và xuất khẩu cá tra. Với hơn mười một năm hoạt động, một thời gian không tính là dài đối với một doanh nghiệp nhưng Công ty TNHH Hùng Cá đã không ngừng phát triển, ngày càng mở rộng quy mô theo chuỗi mô hình khép kín. Thế nhưng, cũng giống như bao công ty khác, Hùng Cá đang đối mặt với sự ra đi của các nhân sự giỏi, sự ra đi của các công nhân lành nghề. Từ năm 2015 đến năm 2019, Hùng Cá đã có sự biến động khá lớn về nhân sự, có 213 người lao động tự nguyện xin thôi việc để chuyển sang làm việc cho các công ty khác hoặc tự mình kinh doanh. Điều này phần nào ảnh hưởng đến hiệu quả 
sản xuất kinh doanh và công tác quản lý, điều hành của Công ty Hùng Cá (Nguyễn Thị Ngọc Châu, 2018).

Chúng ta biết rằng những con người mới - những cán bộ, nhân viên mới sẽ mang lại hơi thở mới, luồng gió mới cho công ty nhưng liệu họ có thể trung thành, gắn kết với công ty hay không phải đợi thời gian trả lời. Để bù đắp cho sự biến động về nhân sự này, Hùng Cá đã không ngừng tuyển mộ nhân viên thế nhưng hiện nay, việc tuyển dụng được nhân sự phù hợp với doanh nghiệp là chuyện không phải dễ dàng. Tình trạng thất nghiệp nhiều nhưng nguồn nhân sự thích hợp với doanh nghiệp lại khủng hoảng thiếu. Vì vậy, Công ty Hùng Cá luôn tìm biện pháp để giữ chân nhân viên, tìm biện pháp để làm cho nhân viên gắn kết với doanh nghiệp hơn nữa bởi việc tuyển dụng được nhân sự thích hợp mất nhiều thời gian, guồng máy công việc cũng vì nguyên nhân này mà chậm trễ. Thế nhưng từ trước đến nay, Công ty Hùng Cá chưa có bất kỳ nghiên cứu chính thức nào về vấn đề này. Xuất phát từ những vấn đề trên, nhóm tác giả cho rằng nghiên cứu các yếu tố ảnh hưởng đến sự gắn kết của nhân viên với Công ty TNHH Hùng Cá là thực sự cần thiết.

\section{Cơ sở lý thuyết}

\subsection{Sụ gắn kết với tổ chức}

Sự gắn kết là ý định gắn kết lâu dài với tổ chức. Bởi sự gắn kết của mỗi cá nhân không chỉ đơn giản là vấn đề của cá nhân mà đó là một mắt xích trong chuỗi làm việc tận tâm cống hiến nhằm đạt mục tiêu tổ chức đề ra. Đến nay, có rất nhiều quan điểm, ý kiến khác nhau của các nhà nghiên cứu trong việc định nghĩa sự gắn kết của nhân viên với tổ chức. Theo Porter và cộng sự (1974), gắn kết với tổ chức là niềm tin mạnh mẽ và chấp nhận các mục tiêu của tổ chức, sã̃n sàng nỗ lực hết mình vì tổ chức và mong muốn duy trì là thành viên của tổ chức. Sự gắn kết với tổ chức là sự sẵn sàng ở lại với tư cách là một thành viên của tổ chức, sẵn sàng nỗ lực vì tổ chức và ủng hộ mục tiêu, giá trị của tổ chức (Dubin \& cộng sự, 1975). Tuy nhiên, Meyer và Allen (1997) cho rằng gắn kết với tổ chức là ở lại với tổ chức, tham gia công việc thường xuyên, nỗ lực làm việc mỗi ngày, bảo vệ tài sản của tổ chức và tin vào mục tiêu của tổ chức. Với Cohen (2007), sự gắn kết với tổ chức là lòng trung thành của nhân viên với tổ chức, sẵn sàng nỗ lực hết mình vì mục tiêu, giá trị của tổ chức và mong muốn duy trì là thành viên của tổ chức. Theo Macey và Schneider (2008) cho rằng sự gắn kết với tổ chức là sự sẵn sàng làm việc tích cực vì tổ chức, cảm thấy tự hào là một thành viên của tổ chức và có sự gắn bó chặt chẽ với tổ chức.

Như vậy, sự gắn kết của nhân viên với tổ chức là trạng thái tâm lý thể hiện sự gắn kết của một cá nhân với một tổ chức, với nghề nghiệp; đó là lòng trung thành và sự nhiệt tình làm việc của nhân viên đối với tổ chức; đó là sự sẵn sàng nỗ lực hết mình vì tổ chức, luôn đặt lợi ích của tổ chức lên trên lợi ích của bản thân mình. Những cá nhân có mức độ gắn kết với tổ chức càng cao sẽ càng hài lòng với công việc của họ, sẽ ít nghĩ đến việc rời bỏ và gắn kết với tổ chức khác.

\subsection{Các thành phần của sụ gắn kết với tổ chức \\ Sự gắn kết với tổ chức đã được định nghĩa và được đo lường bằng nhiều thang đo khác nhau. Theo Meyer và Allen (1991) đề xuất ba thành phần gắn kết với tổ chức: Gắn kết vì tình cảm (Affective commitment): đề cập đến sự gắn kết tình}


cảm, sự gắn kết chặt chẽ và dồn hết tâm trí vào trong tổ chức của nhân viên; Gắn kết do bắt buộc (Continuance commitment): gắn kết do người nhân viên nhận thấy chi phí phải trả cao (chi phí cơ hội) khi phải rời bỏ tổ chức; Gắn kết vì quy chuẩn (Normative commitment): phản ánh gắn kết dựa trên nghĩa vụ của nhân viên đối với tổ chức. Định nghĩa của Meyer và Allen (1991) được chấp nhận và sử dụng nhiều nhất trong các nghiên cứu hiện nay, có ba dạng gắn kết “ tình cảm”, "bắt buộc", và “ quy chuẩn”.

Tuy nhiên, trong nghiên cứu phân tích tổng hợp các tiền đề, tương quan và kết quả của ba thành phần gắn kết "Gắn kết vì tình cảm", "Gắn kết do bắt buộc" và "Gắn kết vì quy chuẩn", Meyer và Allen (1991) đã phát hiện ra rằng ba thành phần gắn kết này có liên quan với nhau và liên quan với mức độ không đồng đều. Trong đó, "Gắn kết vì tình cảm" có mối tương quan mạnh nhất và phù hợp nhất đến các vấn đề liên quan của tổ chức (sự tham gia, kết quả kinh doanh, hành vi của nhân viên trong tổ chức). "Gắn kết do quy chuẩn" cũng có mối tương quan nhưng không cao và "Gắn kết do bắt buộc" hầu như không liên quan (Hà Nam Khánh Giao \& Bùi Nhất Vương, 2016). Vì "Gắn kết vì tình cảm" có mối tương quan mạnh nhất nên trong nghiên cứu này tác giả chỉ chọn thành phần "Gắn kết vì tình cảm" làm biến phụ thuộc để đo lường cho sự gắn kết với tổ chức của nhân viên đang làm việc tại Công ty TNHH Hùng Cá.

\section{Giả thuyết nghiên cứu}

\subsection{Thu nhạp}

Theo Armstrong và Taylor (2017), thu nhập là khoản thanh toán cho công việc, có thể có nhiều hình thức khác nhau bao gồm mức lương cơ bản, tiền lương bổ sung trả bằng tiền mặt ví dụ như trả tiền theo ca, tiền giờ làm thêm và phúc lợi. Tuy nhiên, theo Dessler (2019), thu nhập là khoản thù lao thuộc về tài chính và phi tài chính do người chủ trả bởi thời gian, kỹ năng và nỗ lực làm việc của nhân viên để hoàn thành công việc nhằm đạt mục tiêu tổ chức. Theo báo cáo khảo sát thực trạng quản trị nhân sự tại doanh nghiệp Việt Nam cho thấy nguyên nhân nghỉ việc của nhân viên vì thu nhập chiếm gần $40 \%$ và $24 \%$ người tham gia khảo sát cũng cho rằng lý do chính khiến họ tìm kiếm công việc mới là vì thu nhập (VietnamWorks, 2018). Một khi thỏa mãn với thu nhập sẽ làm nhân viên muốn gắn kết hơn cùng tổ chức, nỗ lực hơn vì tổ chức (Suma \& Lesha, 2013). Do đó, giả thuyết $\mathrm{H}_{1}$ được đề xuất như sau:

$H_{1}$ : Thu nhập ảnh hưởng tích cực đến sự gắn kết của nhân viên với tổ chức.

\subsection{Khen thưởng và phúc lọi}

Khen thưởng là việc ghi nhận, biểu dương, tôn vinh công trạng và khuyến khích bằng lợi ích vật chất hoặc tinh thần đối với cá nhân, tập thể có thành tích trong tổ chức. Khen thưởng đúng người, đúng việc, kịp thời có tác dụng động viên và thúc đẩy sự gắn kết của người lao động đối với tổ chức. Phúc lợi là phần thù lao gián tiếp được trả dưới dạng các hỗ trợ về cuộc sống cho người lao động (Dessler, 2019) . Các khoản tiền tuy gọi là thưởng nhưng lại trả bằng nhau cho nhân viên không phân biệt kết quả làm việc như "thưởng" trong các ngày lễ, “tháng lương thứ 13"... về bản chất là phúc lợi. Tất cả những nhân viên đều muốn được khen thưởng cho những cống hiến hoặc đóng góp của họ theo những cách thức nhất định. Nhân viên có thể nhận được ở tổ chức không phải chỉ có tiền và hơn nữa không phải tất cả mọi người làm việc đều vì tiền. Tiền sẽ là nhân tố động viên mạnh mẽ đối 
với những người lao động có trình độ thấp và những người theo đuổi sự giàu có về vật chất, song tiền có sự ảnh hưởng ít đến những người thích được làm những công việc mang tính thách thức. Do đó, việc khen thưởng phải hướng tới việc thỏa mãn các nhu cầu cá nhân của người lao động. Bên cạnh đó, sự khen thưởng tương xứng với thành tích đóng góp, chính sách phúc lợi đa dạng và phong phú sẽ thể hiện sự quan tâm của doanh nghiệp đến nhân viên, làm cho nhân viên cảm thấy hài lòng với chính sách khen thưởng và phúc lợi của công ty. Một khi hài lòng với chính sách khen thưởng và phúc lợi sẽ làm nhân viên muốn gắn kết với tổ chức hơn (Vuong \& Suntrayuth, 2020). Do đó, giả thuyết $\mathrm{H}_{2}$ được đề xuất như sau:

$\mathrm{H}_{2}$ : Chinh sách khen thương và phúc lọi ảnh huơong tích cưc đến sụ gắn kết của nhân viên với tổ chức.

\subsection{Môi trưòng làm việc}

Môi trường làm việc trong tổ chức bao gồm môi trường vật chất và môi trường tâm lý. Môi trường vật chất bao gồm vị trí nơi làm việc, không gian làm việc, điều kiện làm việc. Môi trường vật chất phù hợp, tiện lợi chắc chắn sẽ tạo điều kiện lớn để người lao động tăng cường sự gắn kết với tổ chức. Môi trường tâm lý bao gồm những áp lực công việc, bầu không khí làm việc.... Một bầu không khí làm việc thân thiện, vui vẻ, hòa đồng chắc chắn sẽ làm tăng sự tự tin đối với mỗi người lao động, kích thích tinh thần sáng tạo, tăng sự gắn kết của người lao động với tổ chức. Theo Armstrong và Taylor (2017), khi tổ chức có một môi trường làm việc tốt thì sự gắn kết của nhân viên với tổ chức càng cao. Theo nghiên cứu của Hanaysha (2016) đã cho thấy mối quan hệ giữa môi trường làm việc và sự gắn kết của nhân viên với tổ chức. Môi trường làm việc luôn được người lao động quan tâm bởi vì liên quan tới sự thuận tiện cá nhân song đồng thời nó cũng là nhân tố giúp họ hoàn thành tốt nhiệm vụ. Môi trường làm việc tốt sẽ nâng cao hơn nữa sự gắn kết của nhân viên. Do đó, giả thuyết $\mathrm{H}_{3}$ được đề xuất như sau:

H3: Môi trường làm việc ảnh hưởng tích cực đến sự gắn kết của nhân viên với tổ chíc.

\section{4. Đồng nghiệp}

Đồng nghiệp là những cảm nhận liên quan các hành vi, quan hệ với đồng nghiệp trong công việc. Sự phối hợp và giúp đỡ nhau trong công việc hay việc ganh đua, cạnh tranh, thiếu nhiệt tình trong hợp tác cũng ảnh hưởng đến sự gắn kết của nhân viên. Bởi đồng nghiệp là những người mà chúng ta đôi khi gặp nhiều hơn cả gia đình và bạn bè. Vì vậy, sự ủng hộ và tôn trọng của đồng nghiệp luôn là yếu tố để tạo nên thành công trong công việc. Suma và Lesha (2013) đã cho thấy mối quan hệ giữa đồng nghiệp với sự gắn kết của nhân viên với tổ chức. Nếu nhân viên được làm việc trong tổ chức mà có sự phối hợp, tình cảm yêu thương và giúp đỡ lẫn nhau giữa các đồng nghiệp sẽ làm cho nhân viên cảm thấy hạnh phúc từ đó càng gắn kết với tổ chức cao hơn. Do đó, giả thuyết $\mathrm{H}_{4}$ được đề xuất như sau:

H4: Đồng nghiệp ảnh huơong tích cục đến sự gắn kết của nhân viên với tổ chức.

\subsection{Ngưòi quản lý trục tiếp}

Người quản lý trực tiếp là người chịu trách nhiệm điều hành, quản lý, phân công công việc, tổ chức đào tạo, giám sát và phát triển đội ngũ nhân viên kế thừa. Một công ty có thể có môi trường làm việc tốt, chế độ lương thưởng, phúc lợi hay chính sách đãi ngộ tốt cho nhân viên, nhưng một người 
lãnh đạo kém cỏi có thể vô hiệu hóa những ưu điểm này và có thể làm tăng sự bất mãn cho nhân viên. Theo nghiên cứu của Dessler (2019), nhân viên có quan hệ tốt với các nhà quản lý trực tiếp của mình có sự gắn kết cao hơn. Armstrong và Taylor (2017) cho rằng người quản lý trực tiếp là tiền đề quan trọng của sự gắn kết của nhân viên với tổ chức. Theo Talukder (2019) và Suma và Lesha (2013), người quản lý trực tiếp được xem là con đường dẫn đến sự gắn kết của nhân viên đối với tổ chức. Do đó, giả thuyết $\mathrm{H}_{5}$ được đề xuất như sau:

H5: Nguoơi quản lý trục tiếp ảnh huởng tích cực đến sụ gắn kết của nhân viên với tổ chíc.

\subsection{Cơ hội thăng tiến}

Thăng tiến là sự tiến bộ về chuyên môn, về cấp bậc, địa vị trong công việc. Cơ hội phát triển nghề nghiệp được hiểu như các bước tiến trong nghề nghiệp, thăng tiến trong công việc đồng nghĩa với việc cấp trên nhìn nhận vào năng lực làm việc và sự phấn đấu của nhân viên chứ không chỉ nhờ vào mối quan hệ. Thăng tiến đó là cái đích hướng tới của người nhân viên khi bắt đầu một công việc. Tuy nhiên, để đạt được điều đó thì lại không phải dễ dàng. Cơ hội thăng tiến góp phần kích thích nhân viên nỗ lực hơn trong công việc, họ sẽ cố gắng hết mình để đạt được mục tiêu trong thăng tiến. Một tổ chức có chương trình đào tạo và phát triển thăng tiến khoa học, hợp lý sẽ thúc đẩy sự gắn kết của nhân viên với tổ chức càng cao. Hà Nam Khánh Giao và Bùi Nhất Vương (2016) cho rằng khi tổ chức cung cấp cơ hội đào tạo và thăng tiến làm cho nhân viên cảm thấy rằng tổ chức đã xem trọng họ và điều này làm tăng sự gắn kết của họ với tổ chức hơn (Kumaran \& Sivasubramanian, 2013; Suma \& Lesha, 2013). Do đó, giả thuyết $\mathrm{H}_{6}$ được đề xuất như sau:

H6: Co hội thăng tiến ảnh hưởng tích cực đến sự gắn kết của nhân viên với tổ chức.

\subsection{Văn hóa tổ chúc}

Theo Robbins (2015), văn hóa tổ chức là một hệ thống ý nghĩa chung hàm giữ bởi các thành viên của tổ chức, qua đó có thể phân biệt tổ chức này với tổ chức khác. Với (Armstrong \& Taylor, 2017), văn hóa tổ chức gồm các tiêu chuẩn và quy tắc của tổ chức quy định cách thức ứng xử nhân viên trong tổ chức. Như vậy, văn hóa tổ chức là hệ thống bao gồm các giá trị, niềm tin và các khuôn mẫu hành vi ứng xử hình thành nên bản sắc riêng của tổ chức. Nghiên cứu của Hà Nam Khánh Giao và Bùi Nhất Vương (2016) khám phá rằng các công ty có văn hóa trong công việc có lực lượng nhân sự gắn kết hơn. Theo nghiên cứu của VietnamWorks (2018), 13\% người tham gia khảo sát tại Việt Nam họ có dự định tìm kiếm công việc mới bởi vì họ cảm thấy không phù hợp với văn hóa tổ chức tại công ty mà họ đang làm việc. Như vậy, khi một doanh nghiệp, tổ chức có các giá trị văn hóa lành mạnh, vững chắc thì sẽ có tác dụng như một chất keo kết dính nhân viên cam kết ở lại phục vụ cho tổ chức lâu dài. Do đó, giả thuyết $\mathrm{H}_{7}$ được đề xuất như sau:

H7: Văn hóa tổ chức ảnh hwởng tích cực đến sự gắn kết của nhân viên với tổ chức. 


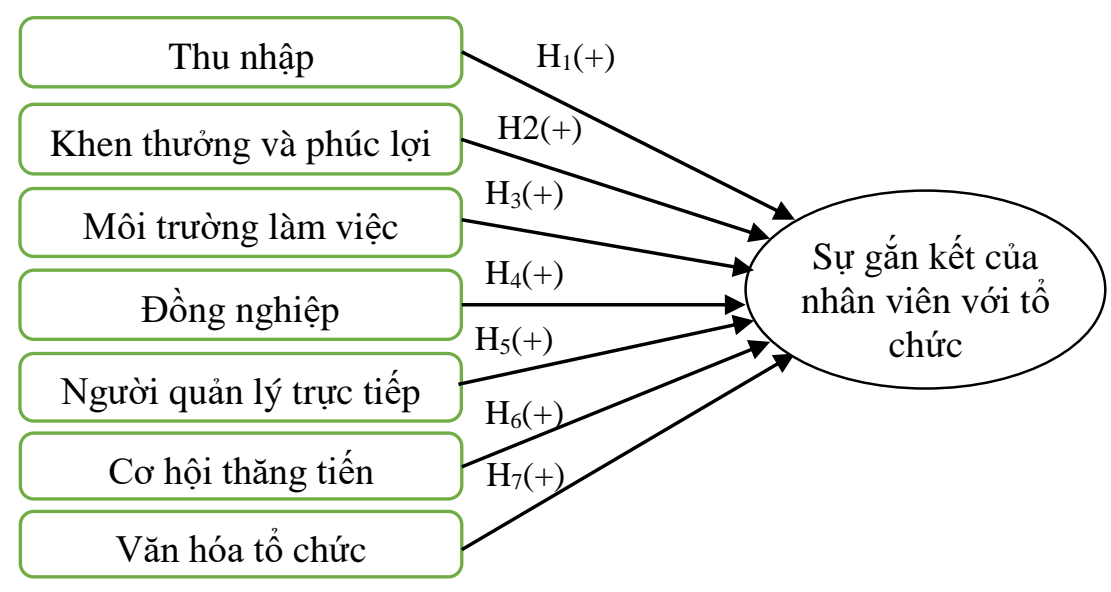

Hình 1. Mô hình nghiên cứu

\section{Kết quả nghiên cứu}

\subsection{Mô tả dũ liệu}

Nghiên cứu được thực hiện với đối tượng khảo sát là nhân viên đang làm việc tại Công ty Hùng Cá. Tổng cộng có 400 bảng câu hỏi được phát ra và thu về 350 bảng câu hỏi, sau khi loại bỏ các phiếu trả lời không đạt yêu cầu, còn lại là 327 bảng, đạt tỷ lệ 81,75\%. Bảng câu hỏi được mã hoá và đưa vào xử lý số liệu bằng phần mềm SPSS 20.0 để phân tích. Tác giả tiến hành phân loại 327 nhân viên được khảo sát theo thành phần giới tính, độ tuổi, trình độ học vấn, thời gian làm việc, vị trí/cấp bậc và thu nhập. Kết quả thông tin nhân khẩu học được trình bày trong Bảng 1 .

Bảng 1. Thống kê mô tả đặc điểm nhân khẩu học

\begin{tabular}{cccc}
\hline & & Tổng & Tần số \\
\hline \multirow{2}{*}{ Giới tính } & Nam & 120 & 36,7 \\
& Nữ & 207 & 63,3 \\
Độ tuổi & Dưới 30 tuổi & 250 & 76,5 \\
& Từ 30-55 tuổi & 77 & 23,5 \\
& Từ trung học chuyên nghiệp & 260 & 79,5 \\
Trình độ & trở xuống & 64 & 19,6 \\
học vấn & Cao đẳng, đại học & 3 & 0,9 \\
& Trên đại học & 189 & 57,8 \\
Thời gian & Dưới 3 năm & 100 & 30,6 \\
làm việc & Từ 3-5 năm & 38 & 11,6 \\
& Trên 5 năm & 13 & 3,4 \\
\multirow{2}{*}{ Thu nhập } & Dưới 5 triệu & 295 & 0,9 \\
& Từ 5-10 triệu & 19 & 16,2 \\
\hline
\end{tabular}




\section{2. Đánh giá độ tin cậy của thang đo}

Thang đo trước hết sẽ được phân tích hệ số tin cậy Cronbach's Alpha, các biến có hệ số tương quan tổng (item-total correlation) nhỏ hơn 0,3 sẽ bị loại và thang đo được chấp nhận để phân tích trong các bước tiếp theo khi có độ tin cậy Cronbach's Alpha từ 0,6 trở lên ( Hà Nam Khánh Giao \& Bùi Nhất Vương, 2019).

Bảng 2. Kết quả phân tích Cronbach's alpha và tương quan biến- tổng

\begin{tabular}{lccc}
\hline \multicolumn{1}{c}{ Thang đo } & $\begin{array}{c}\text { Số biến } \\
\text { quan sát }\end{array}$ & $\begin{array}{c}\text { Cronbach's } \\
\text { alpha }\end{array}$ & $\begin{array}{c}\text { Hệ số } \\
\text { tương quan biến- } \\
\text { tổng nhỏ nhất }\end{array}$ \\
\hline Thu nhập & 5 & 0,936 & 0,773 \\
Khen thưởng và phúc lợi & 5 & 0,906 & 0,699 \\
Môi trường làm việc & 5 & 0,839 & 0,602 \\
Đồng nghiệp & 4 & 0,846 & 0,569 \\
Người quản lý trực tiếp & 5 & 0,794 & 0,513 \\
Cơ hội thăng tiến & 4 & 0,744 & 0,374 \\
Văn hóa tổ chức & 4 & 0,822 & 0,560 \\
Sự gắn kết của nhân viên với tổ chức & 4 & 0,852 & 0,608 \\
\hline
\end{tabular}

Dựa vào Bảng 2 , kết quả phân tích cho thấy rằng giá trị của của Conbach's Alpha giao động trong phạm vi từ 0,744 đến 0,936 , và hệ số tương biến tổng nhỏ nhất của mỗi biến đều lớn hơn 0,3 . Do đó, các thang đo đã đạt được độ tin vậy và sẽ được sử dụng để phân tích nhân tố khám phá.

\subsection{Phân tích nhân tố khám phá EFA}

Kết quả phân tích nhân tố khám phá lần 1 cho thấy Kiểm định $\mathrm{KMO}$ và Bartlett's trong phân tích nhân tố cho thấy Sig. = 0,000 (Sig. = 0,000 < 0,05); hệ số KMO đạt $0,757(>0,5)$. Kết quả này chỉ ra rằng các biến quan sát trong tổng thể có mối tương quan với nhau và phân tích nhân tố EFA rất thích hợp. Tại các mức giá trị Eigenvalues lớn hơn 1 và với phương pháp rút trích principal components và phép quay varimax, phân tích nhân tố đã trích được 07 nhân tố từ 33 biến quan sát và với tổng phương sai trích là $66,430 \%$ (lớn hơn $50 \%$ ) đạt yêu cầu. Tuy nhiên, biến TN5 có chênh lệch giữa hệ số tải trên hai nhân tố thứ 1 và nhân tố thứ 2 là $0,213<0,3$ nên biến TN5 bị loại khỏi thang đo của yếu tố Thu nhập. 
Bảng 3. Kết quả EFA biến độc lập lần 2

\begin{tabular}{|c|c|c|c|c|c|c|c|}
\hline \multirow{2}{*}{ Biến quan sát } & \multicolumn{7}{|c|}{ Hệ số nhân tố tải } \\
\hline & 1 & 2 & 3 & 4 & 5 & 6 & 7 \\
\hline KT3 & 0,905 & & & & & & \\
\hline KT4 & 0,878 & & & & & & \\
\hline KT2 & 0,855 & & & & & & \\
\hline KT5 & 0,764 & & & & & & \\
\hline KT1 & 0,706 & & & & & & \\
\hline $\mathrm{TN} 2$ & & 0,949 & & & & & \\
\hline TN1 & & 0,860 & & & & & \\
\hline TN3 & & 0,836 & & & & & \\
\hline TN4 & & 0,833 & & & & & \\
\hline DN2 & & & 0,871 & & & & \\
\hline DN3 & & & 0,854 & & & & \\
\hline DN4 & & & 0,785 & & & & \\
\hline DN1 & & & 0,705 & & & & \\
\hline DN5 & & & 0,702 & & & & \\
\hline MT1 & & & & 0,828 & & & \\
\hline MT3 & & & & 0,818 & & & \\
\hline MT5 & & & & 0,748 & & & \\
\hline MT2 & & & & 0,745 & & & \\
\hline MT4 & & & & 0,743 & & & \\
\hline QL3 & & & & & 0,775 & & \\
\hline QL5 & & & & & 0,772 & & \\
\hline QL1 & & & & & 0,747 & & \\
\hline QL4 & & & & & 0,701 & & \\
\hline QL2 & & & & & 0,687 & & \\
\hline VH2 & & & & & & 0,871 & \\
\hline VH3 & & & & & & 0,855 & \\
\hline VH1 & & & & & & 0,736 & \\
\hline VH4 & & & & & & 0,734 & \\
\hline $\mathrm{CH} 4$ & & & & & & & 0,760 \\
\hline $\mathrm{CH} 2$ & & & & & & & 0,697 \\
\hline $\mathrm{CH} 1$ & & & & & & & 0,661 \\
\hline $\mathrm{CH} 3$ & & & & & & & 0,631 \\
\hline Eigenvalue & 5,405 & 3,512 & 3,226 & 2,839 & 2,344 & 2,080 & 1,784 \\
\hline Phương sai tích lũy (\%) & 16,890 & 27,864 & 37,947 & 46,819 & 54,145 & 60,644 & 66,220 \\
\hline & Ki & $\begin{array}{r}\text { KMC } \\
\text { định Bar }\end{array}$ & $\begin{array}{l}=0,734 \\
\text { tt's: Sig. }\end{array}$ & 0,000 & & & \\
\hline
\end{tabular}

Sau khi loại biến TN5, tác giả tiến hành phân tích nhân tố khám phá lần 2 (Bảng 3). Kết quả phân tích cho thấy tổng phương sai trích đạt 66,220\% (lớn hơn 50\%). Hệ số KMO đạt 0,734 (lớn hơn 0,5 và nhỏ hơn 1 ).
Kiểm định Bartlett's có Sig. = 0,000 (nhỏ hơn 0,05). Hệ số Eigenvalue đạt 1,784 (lớn hơn 1). Các chỉ số này đều đạt yêu cầu và hệ số tải nhân tố của các biến quan sát đều lớn hơn 0,5 nên giữ lại tất cả các biến quan sát. 
Bảng 4. Kết quả EFA thang đo sự gắn kết của nhân viên với tổ chức

\begin{tabular}{lc}
\hline \multicolumn{1}{c}{ Biến quan sát } & Hệ số tải nhân tố \\
\hline GK2 & 0,898 \\
GK4 & 0,857 \\
GK3 & 0,807 \\
GK1 & 0,767 \\
Eigenvalue & 2,780 \\
Phương sai trích (\%) & 69,511 \\
\hline \multicolumn{2}{c}{ KMO = 2,755} \\
Kiểm định Bartlett's: Sig. $=0,000$ \\
\hline
\end{tabular}

Sau khi tiến hành phân tích nhân tố cho biến phụ thuộc, kết quả cho thấy kiểm định KMO và Bartlett's trong phân tích nhân tố cho thấy Sig. = 0,000 (Sig. = 0,000<0,05); hệ số KMO đạt 0,755 (>0,5). Kết quả này chỉ ra rằng các biến quan sát trong tổng thể có mối tương quan với nhau và phân tích nhân tố EFA rất thích hợp.

Như được thể hiện trong Bảng 4, kết quả phân tích EFA cho thấy, với phương pháp trích nhân tố principal component, phép quay Varimax cho phép trích được một nhân tố với 4 biến quan sát và phương sai trích đạt 69,511\% (> 50\%), giá trị Eigenvalue là 2,780 (đạt yêu cầu
Eigenvalue >1), các hệ số tải nhân tố của các biến quan sát đều lớn hơn 0,5 . Vì vậy, thang đo đạt yêu cầu.

\subsection{Phân tích tương quan}

Trước khi tiến hành phân tích hồi quy, tác giả sử dụng hệ số tương quan Pearson để lượng hóa mức độ chặt chẽ của mối liên hệ tuyến tính giữa hai biến độc lập và phụ thuộc (Vuong \& Giao, 2020). Trong phân tích tương quan Pearson, không có sự phân biệt giữa biến độc lập và biến phụ thuộc mà tất cả các biến đều được xem xét như nhau. Tuy nhiên, nếu các biến có tương quan chặt thì phải lưu ý đến vấn đề đa cộng tuyến sau khi phân tích hồi quy.

Bảng 5. Ma trận hệ số tương quan

\begin{tabular}{|c|c|c|c|c|c|c|c|c|c|}
\hline & & $\mathbf{T N}$ & KT & MT & DN & QL & $\mathrm{CH}$ & VH & GK \\
\hline \multirow{2}{*}{$\mathbf{T N}$} & Hệ số & 1 & $-0,141$ & $-0,025$ & 0,193 & $-0,062$ & $-0,077$ & $-0,036$ & 0,533 \\
\hline & Mức ý nghĩa & & 0,010 & 0,651 & 0,000 & 0,265 & 0,162 & 0,518 & 0,000 \\
\hline \multirow{2}{*}{ KT } & Hệ số & & 1 & 0,179 & $-0,061$ & $-0,089$ & $-0,005$ & 0,142 & 0,286 \\
\hline & Mức ý nghĩa & & & 0,001 & 0,275 & 0,108 & 0,928 & 0,010 & 0,000 \\
\hline \multirow{2}{*}{ MT } & Hệ số & & & 1 & $-0,108$ & $-0,033$ & $-0,049$ & 0,084 & 0,205 \\
\hline & Mức ý nghĩa & & & & 0,051 & 0,552 & 0,378 & 0,131 & 0,000 \\
\hline DN & Hệ số & & & & 1 & 0,212 & 0,031 & $-0,698$ & 0,186 \\
\hline
\end{tabular}




\begin{tabular}{|c|c|c|c|c|c|c|c|c|c|}
\hline & & TN & KT & MT & DN & QL & $\mathbf{C H}$ & VH & GK \\
\hline & Mức ý nghĩa & & & & & 0,000 & 0,578 & 0,000 & 0,001 \\
\hline \multirow{2}{*}{ QL } & Hệ số & & & & & 1 & 0,072 & $-0,024$ & 0,183 \\
\hline & Mức ý nghĩa & & & & & & 0,193 & 0,660 & 0,001 \\
\hline \multirow{2}{*}{ CH } & Hệ số & & & & & & 1 & 0,088 & 0,104 \\
\hline & Mức ý nghĩa & & & & & & & 0,113 & 0,040 \\
\hline \multirow{2}{*}{ VH } & Hệ số & & & & & & & 1 & 0,075 \\
\hline & Mức ý nghĩa & & & & & & & & 0,016 \\
\hline \multirow{2}{*}{ GK } & Hệ số & 0,533 & 0,286 & 0,205 & 0,186 & 0,183 & 0,104 & 0,075 & 1 \\
\hline & Mức ý nghĩa & 0,000 & 0,000 & 0,000 & 0,001 & 0,001 & 0,040 & 0,016 & 0,000 \\
\hline
\end{tabular}

Dựa vào Bảng 5 , kết quả phân tích tương quan cho thấy rằng mức ý nghĩa của các hệ số rất nhỏ $($ sig. $=0<0,05)$ nên các hệ số tương quan có ý nghĩa thống kê và đều đủ điều kiện để đưa vào phân tích hồi quy.

\subsection{Phân tích hồi quy tuyến tính}

Bảng 6. Thống kê phân tích các hệ số hồi quy

\begin{tabular}{|c|c|c|c|c|c|c|c|}
\hline \multirow{2}{*}{ Mô hình } & \multicolumn{3}{|c|}{ Hệ số chưa chuẩn hóa Hệ số chuẩn hóa } & \multirow[t]{2}{*}{ 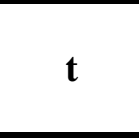 } & \multirow{2}{*}{ Sig. } & \multicolumn{2}{|c|}{ Thống kê đa cộng tuyến } \\
\hline & B & Sai số chuẩn & Beta & & & Dung sai & VIF \\
\hline (Hằng số) & 0,540 & 0,230 & & 2,350 & 0,019 & & \\
\hline $\mathrm{TN}$ & 0,355 & 0,024 & 0,584 & 14,488 & 0,000 & 0,888 & 1,126 \\
\hline KT & 0,237 & 0,027 & 0,347 & 8,692 & 0,000 & 0,908 & 1,101 \\
\hline MT & 0,145 & 0,032 & 0,177 & 4,544 & 0,000 & 0,956 & 1,046 \\
\hline $\mathrm{DN}$ & 0,199 & 0,073 & 0,158 & 2,713 & 0,007 & 0,424 & 2,356 \\
\hline QL & 0,204 & 0,038 & 0,216 & 5,374 & 0,000 & 0,893 & 1,120 \\
\hline $\mathrm{CH}$ & 0,111 & 0,034 & 0,127 & 3,279 & 0,001 & 0,960 & 1,041 \\
\hline $\mathrm{VH}$ & 0,096 & 0,039 & 0,137 & 2,425 & 0,016 & 0,455 & 2,197 \\
\hline
\end{tabular}

$\mathrm{R}^{2}$ hiệu chỉnh: 0,529

Thống kê F (ANOVA): 53,341

Mức ý nghĩa (Sig. của ANOVA): 0.000

Durbin-Watson: 1,944

Giá trị $\mathrm{R}^{2}$ hiệu chỉnh bằng 0,529 có nghĩa là $52,90 \%$ sự biến thiên của biến phụ
Trên cơ sở các biến độc lập và biến phụ thuộc đã được xem xét mối tương quan tuyến tính, tác giả tiếp tục sử dụng phân tích hồi quy bội để tìm thấy mối quan hệ giữa các khái niệm này. 
thuộc được giải thích bởi sự biến thiên của 7 biến độc lập. Kiểm định $\mathrm{F}$ sử dụng trong phân tích phương sai (Anova) là phép kiểm định giả thuyết về độ phù hợp của mô hình hồi quy tuyến tính tổng thể. Trong bảng phân tích (Bảng 6), cho thấy trị số $\mathrm{F}$ có mức ý nghĩa với Sig. $=0,000(<0,05)$ có nghĩa mô hình hồi quy tuyến tính đưa ra là phù hợp với dữ liệu thực tế thu thập được và các biến đưa vào đều có ý nghĩa trong thống kê với mức ý nghĩa $5 \%$. Ngoài ra, kiểm định Durbin - Watson cho thấy kết quả d $=1,944$ $(1<\mathrm{d}<3)$ nên ta có thể kết luận các phần dư là độc lập với nhau hay không có tương quan giữa các phần dư. Hơn nữa, hệ số phóng đại phương sai VIF (Variance Inflation factor - VIF) đạt giá trị lớn nhất 2,356 (nhỏ hơn 5) cho thấy các biến độc lập này không có quan hệ chặt chẽ với nhau nên không có hiện tượng đa cộng tuyến xảy ra (Giao và cộng sự., 2020). Do đó, mối quan hệ giữa các biến độc lập không ảnh hưởng đáng kể đến kết quả giải thích của mô hình hồi quy. Phương trình hồi quy chưa chuẩn hóa có dạng:

\section{GK $=0,540+0,355^{*} \mathrm{TN}+0,237 * \mathrm{KT}$ $+0,145 * \mathrm{MT}+0,199 * \mathrm{DN}+0,204 * \mathrm{QL}+$ $0,111 * \mathrm{CH}+0,096 * \mathrm{VH}$.}

Các hệ số hồi quy đều mang dấu dương $(+)$ thể hiện các biến độc lập có quan hệ thuận với biến phụ thuộc. Sự gắn kết của nhân viên với tổ chức (GK) chịu tác động mạnh nhất và thấp dần theo thứ tự: Thu nhập $\left(\beta_{1}=0,584\right)$, Khen thưởng và phúc lợi $\left(\beta_{2}=0,347\right)$, Người quản lý trực tiếp $\left(\beta_{5}=0,216\right)$, Môi trường làm việc $\left(\beta_{3}=\right.$ $0,177)$, Đồng nghiệp $\left(\beta_{4}=0,158\right)$, Văn hóa tổ chức $\left(\beta_{7}=0,137\right)$, và Cơ hội thăng tiến $\left(\beta_{6}=0,127\right)$.

\subsection{Các yếu tố ảnh hưởng đến sựgắn kết của nhân viên với tổ chức}

Yếu tố tác động thứ nhất là "Thu nhập", yếu tố này tác động mạnh nhất đến sự gắn kết của nhân viên với Công ty Hùng Cá. Như đã phân tích, yếu tố thu nhập của Công ty Hùng Cá cũng khá cao so với mặt bằng chung của thị trường lao động. Tuy nhiên, với mức sống hiện nay, khi chi phí ngày càng đắt đỏ thì mức thu nhập này cũng chỉ vừa đủ sống. Người nhân viên đi làm không chỉ mong muốn mức thu nhập của mình có thể đảm bảo được cuộc sống mà còn thông qua mức thu nhập để khẳng định địa vị xã hội, sự thành đạt của mình. Vì vậy, thu nhập là vấn đề người lao động quan tâm, liệu làm việc tại Công ty Hùng Cá có mức thu nhập tốt hay không.

Yếu tố tác động thứ hai là "Khen thưởng và phúc lợi”, yếu tố này đóng một vai trò quan trọng trong việc nâng cao sự gắn kết của nhân viên với tổ chức. Khen thưởng và phúc lợi tốt không chỉ thu hút được nhiều người lao động mà còn giữ được chân nhân viên, giữ được người tài. Tuy nhiên, chính sách khen thưởng và phúc lợi tại Công ty Hùng Cá còn nhiều hạn chế như thành tích của người lao động chưa được cấp trên công nhận kịp thời, các chế độ phúc lợi về kiểm tra sức khỏe cho người lao động vẫn chưa được quan tâm sâu sát.

Yếu tố tác động thứ ba là "Người quản lý trực tiếp", yếu tố này cũng có ảnh hưởng quan trọng đến sự gắn kết của nhân viên tại Công ty Hùng Cá. Người quản lý trực tiếp là người làm việc trực tiếp với nhân viên nên họ có thể hiểu rõ nhân viên của mình về năng lực, tính cách, điểm mạnh yếu và định hướng phát triển của từng cá nhân. Đồng thời họ là người trực tiếp hoặc gián tiếp liên quan đến việc xây dựng, hoạch định các chính sách đào tạo thăng tiến cho doanh nghiệp. Tuy nhiên, nếu người quản lý trực 
tiếp không công tư phân minh sẽ làm nhân viên của mình bất mãn và rời bỏ công ty. Tại Công ty Hùng Cá, vẫn tồn tại một số ít ngưởi quản lý trực tiếp chưa được lòng của nhân viên mình. Vì vậy, không khí làm việc giữa nhân viên và người quản lý trực tiếp không được thoải mái. Do đó, sự gắn kết của nhân viên với công ty cũng vì lý do này mà bị ảnh hưởng.

Yếu tố tác động thứ tư là "Môi trường làm việc", yếu tố này đã đóng góp một phần không nhỏ đến sự gắn kết của nhân viên với Công ty Hùng Cá. Với nhân viên khối văn phòng, môi trường làm việc chính là bầu không khí thoải mái khi làm việc, đó là nơi để thể hiện năng lực của bản thân mình.Với công nhân - người tham gia trực tiếp sản xuất thì môi trường làm việc đối với họ chính là sự an toàn lao động. Khi mức độ hài lòng của nhân viên với yếu tố môi trường tăng thì sự gắn kết của họ với doanh nghiệp sẽ tăng. Do đó, Công ty Hùng Cá cần chú trọng cải thiện các điều kiện làm việc, tạo ra bầu không khí làm việc thoải mái, tăng cường đầu tư các phương tiện lao động, các loại bảo hộ lao động phù hợp

Yếu tố tác động thứ năm là "Đồng nghiệp", yếu tố này cũng có sức ảnh hưởng đến sự gắn kết của nhân viên tại Công ty Hùng Cá. Thực tiễn cho thấy rằng, khi những người làm việc chung có sự gắn bó, chia sẻ và giúp đỡ nhau trong công việc và cả trong cuộc sống sẽ tạo nên một môi trường làm việc thân thiện, cởi mở và làm việc hiệu quả hơn. Bởi khi có mối quan hệ tốt với đồng nghiệp, người nhân viên sẽ không cảm thấy chán nản mỗi khi đến nơi làm việc, đó cũng là động lực khiến họ trở nên yêu công việc của mình hơn, những mối quan hệ tốt đẹp này sẽ giúp khích lệ, động viên tinh thần làm việc. Mối quan hệ giữa các nhân viên sẽ thuận lợi hơn cho việc trao đổi kinh nghiệm và giúp đỡ nhau trong công việc. Điều này góp phần không nhỏ vào quyết định ở lại và cống hiến cho sự phát triển của công ty. Do đó, người lao động luôn mong muốn làm việc trong môi trường thân thiện, hòa nhã với mọi người. Một môi trường làm việc với mối quan hệ đồng nghiệp tốt cũng ảnh hưởng đến sự gắn kết của họ đối với doanh nghiệp.

Yếu tố tác động thứ sáu là "Văn hóa tổ chức", yếu tố này cũng ảnh hưởng đến sự gắn kết của nhân viên với Công ty Hùng Cá. Công ty Hùng Cá luôn tạo điều kiện cho nhân viên nâng cao kỹ thuật, chuyên môn. Ngoài ra, công ty luôn có các hoạt động vì cộng đồng, các giá trị văn hóa này góp phần tác động đến thái độ làm việc và lòng tự hào, yêu mến của nhân viên đối với Hùng Cá. Khi Hùng Cá có các giá trị văn hóa lành mạnh, vững chắc thì sẽ có tác dụng như chất keo kết dính nhân viên cam kết ở lại phục vụ cho công ty lâu dài.

Yếu tố tác động thứ bảy là "Cơ hội thăng tiến", yếu tố này tác động yếu nhất đến sự gắn kết của nhân viên tại công ty Hùng Cá. Vì công ty Hùng Cá là công ty gia đình nên hầu hết quản lý cấp cao đều do người thân đảm trách. Tuy nhiên, nhân viên vẫn có cơ hội cho các vị trí quản lý cấp trung. Thực tế tại Hùng Cá, người nhân viên chỉ có cơ hội thăng tiến khi người quản lý trực tiếp của mình chuyển đến vị trí cao hơn hoặc chuyển đến các bộ phận/phòng ban khác. Thế nhưng, công ty luôn có chính sách hoạch định nhân sự kế thừa. Vì vậy đây chính là động lực cho người nhân viên nỗ lực hết sức mình để được tỏa sáng.

\subsection{Thảo luận}

So với nghiên cứu của Suma và Lesha (2013) được thực hiện tại Shkodra, Albania 
với đối tượng khảo sát là nhân viên làm việc trong khối hành chính công, có sự tương đồng về các yếu tố ảnh hưởng là Thu nhập, Người quản lý, Đồng nghiệp, Cơ hội thăng tiến. Tuy nhiên, mức độ ảnh hưởng của các yếu tố không giống nhau khi nghiên cứu tại Công ty Hùng Cá. Ngoài những yếu tố tương đồng trên, nghiên cứu của tác giả đã bổ sung thêm một số yếu tố mới ảnh hưởng đến Sự gắn kết của nhân viên với tổ chức như: Khen thưởng và phúc lợi, Môi trường làm việc, Văn hóa tổ chức. Ngoài ra, trong nghiên cứu của Suma và Lesha (2013) đã cho thấy rằng đặc điểm có mối quan hệ với sự gắn kết của nhân viên với tổ chức. Trong nghiên cứu của tác giả, tác giả chưa tìm thấy mối quan hệ giữa đặc điểm cá nhân với sự gắn kết của nhân viên với tổ chức tại Công ty Hùng Cá.

So với nghiên cứu của Kumaran và Sivasubramanian (2013) được thực hiện tại Công ty Neyveli Lignite ở Ấn Độ với đối tượng khảo sát là nhân viên làm việc tại công ty. Cả hai nghiên cứu đều chỉ ra được mối quan hệ giữa Cơ hội thăng tiến và Sự gắn kết của nhân viên với tổ chức. Tuy nhiên mức độ ảnh hưởng của yếu tố này không giống nhau. Ngoài yếu tố tương đồng trên, nghiên cứu của tác giả đã bổ sung thêm một số yếu tố mới ảnh hưởng đến Sự gắn kết của nhân viên với tổ chức như: Thu nhập, Khen thưởng và phúc lợi, Người quản lý trực tiếp, Môi trường làm việc, Đồng nghiệp,Văn hóa tổ chức. Bên cạnh đó, nghiên cứu của Kumaran và Sivasubramanian (2013) chưa chỉ ra được mối quan hệ giữa đặc điểm cá nhân và sự gắn kết của nhân viên với tổ chức. Kết quả này tương đồng với kết quả nghiên cứu của tác giả tại Công ty Hùng Cá.

\section{8. Đề xuất hàm ý quản trị}

\subsubsection{Thu nhâp}

"Thu nhập" là yếu tố có mức độ ảnh hưởng lớn nhất đến sự gắn kết của nhân viên tại Công ty Hùng Cá (mean = 4,08). Công ty cần xây dựng thang bảng lương với các tiêu chí, yêu cầu cụ thể cho từng vị trí, cần đánh giá đúng vai trò của từng nhân viên trong công ty để họ nhận được những mức thu nhập tương xứng với cống hiến của họ và hợp lý. Đối với nhân viên tham gia trực tiếp sản xuất, đối tượng lao động này thường xuyên biến động, nghỉ việc (do bệnh tật, tai nạn, lương thấp, đối xử thiếu công bằng,...), công ty cần xem xét trả lương, có chế độ, chính sách về lương đặc biệt đối với những đối tượng này để nhằm khuyến khích họ hăng say làm việc, gắn kết với công ty. Trên thực tế có nhiều trường hợp người được tuyển dụng sau, trình độ học vấn thấp hơn nhưng bậc lương cao hơn, hay làm cùng thâm niên nhưng có người được tăng bậc lương và có người thì không,...những trường hợp này ít nhiều gây bất mãn cho người lao động. Vì vậy, để làm được điều này công ty cần có bảng mô tả công việc cho từng vị trí cụ thể. Với một bảng mô tả công việc rõ ràng, từng nhân viên sẽ thấy được vị trí, vai trò và đóng góp của mình cũng như của các thành viên khác. Như vậy, họ sẽ thấy mình được trả lương công bằng và tương xứng.

\subsubsection{Khen thuoơng và phúc lơi}

"Khen thưởng và phúc lợi" là yếu tố có mức độ ảnh hưởng thứ hai đến sự gắn kết của nhân viên tại Công ty Hùng cá (mean = $4,35)$. Công ty cần thông qua các bảng đánh giá chính xác và với sự đánh giá công tâm để đảm bảo sự công bằng cho người lao động. Công ty nên gắn liền việc tăng tiền thưởng với sự phát triển của công ty, để nhân viên hiểu được rằng chỉ khi công ty 
phát đạt, tiền thưởng của mình mới không ngừng được nâng cao. Chính sách khen thưởng có thể thay đổi theo tình hình thực tế của công ty. Vì vậy, công ty cần phải thông báo rõ ràng về tiền thưởng cũng như cách tính tiền thưởng cụ thể đối với từng bộ phận trước khi người lao động nhận được tiền khen thưởng. Về việc khen thưởng thành tích, công ty cũng quy định cụ thể trường hợp nào được ghi nhận cho cá nhân, trường hợp nào được ghi nhận cho tập thể nhằm tránh sự bất mãn, sự đố kỵ giữa nhân viên với nhau.

\subsubsection{Nguoờ quản lý trưc tiếp}

"Người quản lý trực tiếp" là yếu tố có mức độ ảnh hưởng thứ ba đến sự gắn kết của nhân viên tại công ty Hùng Cá (mean = 3,54 ). Kết quả phân tích cho thấy vẫn có sự tồn tại khoảng cách giữa người quản lý trực tiếp và nhân viên. Người quản lý trực tiếp nên tạo ra sự gần gũi, tạo bầu không khí làm việc thân thiện. Bởi có như vậy, người nhân viên mới có thể mạnh dạn trình bày ý kiến, quan điểm cũng như trình bày cách giải quyết vấn đề của họ khi có việc phát sinh. Đồng thời thông qua sự gần gũi này, người quản lý trực tiếp mới có thể hiểu được tâm tư, nguyện vọng nhân viên của mình để từ đó có sự quan tâm, sự động viên, sự chia sẽ đúng lúc, kịp thời. Nhân viên rất mong muốn có được sự tin cậy trong công việc từ người quản lý. Bởi khi tin cậy nhân viên, nhà quản lý sẽ hoàn toàn yên tâm khi giao việc mà không phải lo lắng nhân viên có làm sai hay không hoặc có tiết lộ bí mật cho đối thủ hay không. Người quản lý trực tiếp nên tùy vào công việc mà giao cho nhân viên phù hợp vì họ biết sở trường, sở đoản, điểm mạnh, điểm yếu của từng nhân viên của mình. Có như vậy, người nhân viên mới cảm thấy mình là một thành phần quan trọng trong tổ chức và càng cống hiến hết mình vì tổ chức.

\subsubsection{Môi trường làm việc}

"Môi trường làm việc" là yếu tố có mức độ ảnh hưởng thứ tư đến sự gắn kết của nhân viên với công ty Hùng Cá (mean = 3,76). Công ty cần trang bị cho nhân viên thiết bị đầy đủ hơn và kịp thời hơn. Ví dụ hệ thống máy tính công ty đã khá cũ nhưng công ty vẫn chưa nâng cấp. Vì vậy, công việc của nhân viên thường bị gián đoạn do sự cố máy tính gây nên. Bên cạnh đó, công ty nên cài đặt phần mềm quản lý kho: vật tư, bao bì, hàng hóa và đào tạo nhân viên thực hiện phần mềm này. Đối với khu vực nhập xuất hàng hóa, công ty cần lắp đặt hệ thống camera chất lượng cao nhằm ghi lại các hoạt động xuất nhập hàng hóa một cách chi tiết để cung cấp cho khách hàng khi có yêu cầu. Công ty nên thường xuyên vệ sinh cả bên trong và bên ngoài công ty, thường xuyên vệ sinh cống thoát nước vì công ty chuyên sản xuất cá tra nên các vụn cá, mỡ cá dễ dàng đọng lại từ đó sẽ gây ra ô nhiễm không khí. Bên cạnh đó, công ty thường xuyên tổ chức các lớp đào tạo cho công nhân về an toàn lao động, hướng dẫn cách sử dụng máy móc, thiết bị. Về các công việc đặc thù như nhân viên lái xe nâng, công ty cần gửi đi đào tạo để có sự chuyên nghiệp, không nên để nhân viên tự học hỏi vì độ an toàn sẽ không được đảm bảo.

\subsection{5. Đồng nghiệp}

"Đồng nghiệp" là yếu tố có mức độ ảnh hưởng thứ năm đến sự gắn kết của nhân viên tại công ty Hùng Cá (mean = 3,73). Công ty cần xây dựng mục tiêu tập thể, xây dựng và củng cố tinh thần hợp tác, hỗ trợ lẫn nhau bằng cách khuyến khích nhân viên làm việc theo nhóm để có thể hỗ trợ lẫn nhau, bằng cách phân chia công việc theo 
nhóm và đánh giá kết quả theo nhóm. Lúc đó nhân viên ngoài việc cố gắng hoàn thành nhiệm vụ của mình còn giúp đỡ đồng nghiệp trong công việc của họ. Đồng thời, với khối văn phòng công ty nên tổ chức các buổi chia sẻ thông tin giữa các phòng ban với nhau để nhân viên hiểu công việc nhau hơn và biết vướng mắc ở đâu để hỗ trợ nhau hoàn thành công việc.

\subsubsection{Văn hóa tổ chức}

"Văn hóa tổ chức" là yếu tố có mức độ ảnh hưởng thứ sáu đến sự gắn kết của nhân viên tại Công ty Hùng Cá (mean $=3,38$ ). Công ty không nên giám sát nhân viên khi phân công, giao việc cho họ. Người lãnh đạo nên giao quyền cho nhân viên. Vì giao quyền cho phép nhân viên độc lập suy nghĩ, hành động, kiểm soát và quyết định công việc của chính mình. Họ có thể quyết định thực hiện công việc theo những gì họ tin là đúng và sã̃n sàng chịu trách nhiệm cho kết quả cuối cùng. Chỉ khi để cho nhân viên tự chủ làm việc thì họ mới có thể "trưởng thành". Giao quyền thành công sẽ khuyến khích nhân viên sáng tạo, tạo hứng khởi trong công việc. Vì vậy, để giao quyền cho nhân viên thành công, công ty cần phải chia sẻ mục tiêu của ban lãnh đạo bằng cách cho nhân viên thấy họ là một mắt xích quan trọng trong toàn bộ quy trình hoạt động của công ty. Người lãnh đạo cần chia sẻ và giúp cho nhân viên hiểu rõ nhiệm vụ, hướng phát triển và kế hoạch chiến lược của công ty; các mục tiêu và định hướng công việc để giúp họ đạt được kết quả cao nhất. Đồng thời người lãnh đạo phải cung cấp đầy đủ thông tin và công cụ cần thiết cho nhân viên để họ giải quyết nhiệm vụ được giao.

\subsubsection{Co hội thăng tiến}

"Cơ hội thăng tiến" là yếu tố có mức độ ảnh hưởng yếu nhất đến sự gắn kết của nhân viên tại công ty Hùng Cá (mean = 4,12). Công ty cần chú trọng công tác hoạch định và tạo cơ hội phát triển nghề nghiệp cho nhân viên. Điều này đòi hỏi ban lãnh đạo có sự chỉ đạo sát sao đến các phòng ban, bộ phận sản xuất thực hiện đánh giá, rà soát lại định hướng, quy hoạch phát triển cho từng cá nhân trong bộ phận. Đồng thời, công ty cần xác định lộ trình thăng tiến nghề nghiệp cho nhân viên thông qua các lưu đồ thăng tiến đối với từng chức danh cụ thể. Việc hiểu rõ tâm tư, nguyện vọng của nhân viên và truyền đạt các tiêu chí rõ ràng về cơ hội phát triển là rất cần thiết giúp người lao động nhận thức rõ và có động lực để phấn đấu đạt được mục tiêu thăng tiến trong nghề nghiệp của mình. Đặc biệt, công ty phải ưu tiên đề bạt từ trong nội bộ. Trường hợp, nhân viên được đề bạt còn chưa đủ kinh nghiệm xử lý công việc ở vị trí mới, công ty nên cho người lao động thời gian để thử thách cũng như thời gian để họ tự rèn luyện thêm bản lĩnh của mình.

\section{Kết luận}

Kết quả nghiên cứu cho thấy 07 yếu tố ảnh hưởng đến sự gắn kết của nhân viên với tổ chức. Người lao động hiện tại gắn kết với công ty ở mức độ trung bình (giá trị trung bình $=3,46$ ). Toàn bộ thang đo được sử dụng trong nghiên cứu là đáng tin cậy (Cronbach's Alpha > 0.7). Nghiên cứu chỉ ra rằng có 07 yếu tố có quan hệ đồng biến đến sự gắn kết của nhân viên với tổ chức, sắp xếp theo thứ tự giảm dần: Thu nhập, Khen thưởng và phúc lợi, Người quản lý trực tiếp, Môi trường làm việc, Đồng nghiệp, Văn hóa tổ chức, và Cơ hội thăng tiến. Mặc dù đề tài đã giải quyết xong mục tiêu nghiên cứu đã đề ra, nhưng vẫn còn một số hạn chế như sau: Thứ nhất, đối tượng nghiên cứu là nhân viên đang làm việc tại 
Công ty TNHH Hùng Cá, ở đây bao gồm nhân viên khối văn phòng và công nhân. Tuy nhiên, đề tài chỉ dùng một mô hình nghiên cứu cho cả 2 đối tượng nên chưa thấy được sự khác biệt về sự gắn kết với doanh nghiệp giữa hai đối tượng này. Vì vậy, nghiên cứu tiếp theo cần đưa ra mô hình riêng biệt cho mỗi đối tượng từ đó so sánh để thấy được sự khác biệt về sự gắn kết với công ty giữa nhân viên khối văn phòng và công nhân. Thứ hai, nghiên cứu này chỉ nghiên cứu về sự gắn kết vì tình cảm. Do đó, nghiên cứu tiếp theo nên nghiên cứu cho cả 3 thành phần của sự gắn kết: Gắn kết vì tình cảm, Gắn kết do bắt buộc và Gắn kết vì quy chuẩn.

\section{Ghi chú}

Bài báo là một phần kết quả của nghiên cứu trong Luận văn thạc sĩ của tác giả Nguyễn Thị Ngọc Châu (2018).

\section{Tài liệu tham khảo}

Armstrong, M. and Taylor, S. (2017). Handbook of Human Resource Management Practice. London, United Kingdom: Kogan Page Ltd.

Nguyễn Thị Ngọc Châu (2018). Các yếu tố ảnh huởng đến sự gắn kết của nhân viên với công ty trách nhiệm hũu hạn Hùng Cá. Luận văn Thạc sĩ Quản trị kinh doanh. Trường Đại học Ngoại ngữ - Tin học Tp. Hồ Chí Minh, Hồ Chí Minh, Việt Nam.

Cohen, A. (2007). Commitment before and after: an evaluation and reconceptualization of organizational commitment. Human Resource Management Review, 17, 336-354.

Dessler, G. (2019). Fundamentals of Human Resource Management (5th Ed.). USA: Pearson.

Dubin, R., Champoux, J. and Porter, L. (1975). Central life interests and organizational commitment of blue-collar and clerical workers. Administrative Science Quarterly, 20 (3), 411- 421.

Hà Nam Khánh Giao và Bùi Nhất Vương (2016). Ảnh hưởng của các yếu tố văn hóa doanh nghiệp đến sự gắn bó của nhân viên với tổ chức tại Công ty $\mathrm{CP}$ CMC Telecom Thành Phố Hồ Chí Minh. Tạp chí Kinh tế - Kỹ thuật, 13 (3), 87-101.

Hà Nam Khánh Giao và Bùi Nhất Vương (2019). Giáo Trình Cao Học Phuoong Pháp Nghiên Cúu Khoa Học Trong Kinh Doanh Cập Nhật SmartPLS. TP. Hồ Chí Minh, Việt Nam: Nhà Xuất Bản Tài Chính.

Giao, H. N. K., Vuong, B. N. and Quan, T. N. (2020). The influence of website quality on consumer's e-loyalty through the mediating role of e-trust and e-satisfaction: An evidence from online shopping in Vietnam. Uncertain Supply Chain Management, 8 (2), 351-370. DOI: https://doi.org/10.5257/j.uscm.2019.11.004

Hanaysha, J. (2016). Testing the Effects of Employee Engagement, Work Environment, and Organizational Learning on Organizational Commitment. Procedia - Social and Behavioral Sciences, 229, 289-297.

Kumaran, M. and Sivasubramanian, M. (2013). A study on organisational commitment with special reference to Neyveli Lignite Corporation. IOSR Journal of Business and Management Sciences, 13 (4), 37-40.

Macey, W. H. and Schneider, B. (2008). The meaning of employee engagement. Industrial and Organizational Psychology: Perspectives on Science and Practice, 1, 3-30.

Meyer, J. P. and Allen, N. J. (1991). A threecomponent conceptualization of organizational commitment. Human Resource Management Review, 1, 61-89.

Meyer, J. P. and Allen, N. J. (1997). Commitment in the workplace: Theory, research, and application. Thousand 
Oaks, CA: Sage Publications.

Porter, L. W., Steers, R. M., Mowday, R. T. and Boulian, P. V. (1974). Organizational commitment, job satisfaction, and turnover among psychiatric technicians. Journal of Applied Psychology, 59 (5), 603-609.

Robbins, S. P. (2015). Organizational Behaviour (16th Ed.). Englewood Cliffs, New Jersey: Prentice- Hall.

Suma, S. and Lesha, J. (2013). Job Satisfaction and Organizational commitment: the case of shkodra Municipality. European Scientific Journal, 9, 41-51.

Talukder, A. K. M. M. H. (2019). Supervisor Support and Organizational Commitment: The Role of Work-Family Conflict, Job Satisfaction, and Work-Life Balance. Journal of Employment Counseling, 56
(3), 98-116. DOI: $10.1002 /$ joec. 12125

Vuong, B. N. and Giao, H. N. K. (2020). The impact of perceived brand globalness on consumers' purchase intention and the moderating role of consumer ethnocentrism: An evidence from Vietnam. Journal of International Consumer Marketing, 32 (1), 47-68. DOI: 10.1080/08961530.2019.1619115

Vuong, B. N. and Suntrayuth, S. (2020). The impact of human resource management practices on employee engagement and moderating role of gender and marital status: An evidence from the Vietnamese banking industry. Management Science Letters, 10 (7), 1633-1648. DOI: https://doi.org/10.5267/j.msl.2019.12.003 